\title{
A FORÇA CAMPONESA: TRABALHO E RESISTÊNCIA DE UM REPRESENTANTE DO POVO
}

\author{
Juliana Queiroz ${ }^{1}$
}

\begin{abstract}
Ele não fala para o Povo - é o próprio Povo que fala pela sua voz. Daí a facilidade com que aparentemente era "seguido". Ele extraía da substância do seu ser o que todos queriam e exprimia esse querer comum com as palavras políticas que os outros não sabiam dizer (ou apenas conheciam por intuição, mais ou menos parcial e obscuramente). (...) Militante firme, exemplar, que dava de si tudo que tinha, no entanto ele era o contraste natural e incisivo de qualquer modalidade de comunismo enlatado. Florestan Fernandes ${ }^{2}$
\end{abstract}

As palavras enunciadas por Florestan Fernandes ilustram e sintetizam a legitimidade que Gregório Bezerra possuía como um representante popular; como alguém que compartilhava certas experiências com o povo e também dominava as "palavras políticas", comuns aos membros do partido comunista (PCB). Sua capacidade de expressar o "que os outros não sabiam dizer", se relacionaria à "sua natureza íntima", que fazia - e faz - de Gregório um exemplo de revolucionário; uma espécie de militante autêntico, popular - algo muito distante do "comunismo enlatado", como define Florestan Fernandes. Não por acaso, Gregório é ainda hoje relembrado como uma das principais figuras políticas do país, especialmente entre os trabalhadores rurais. $\mathrm{O}$ reconhecimento da importância de sua figura parece confirmado no sucesso do lançamento da reedição de suas memórias, em 2011.

Filho de camponeses paupérrimos, Gregório Bezerra nasceu no município de Panelas de Miranda, em Pernambuco, em 1900. Conhecido militante do PCB - onde ingressou com 22 anos - Gregório teve uma atuação política durante mais de sessenta anos, desde as primeiras manifestações em 1917 até 1983, ano de seu falecimento. Especialmente após 1945 - quando saiu da prisão - foi perseguido como um dos principais líderes políticos do PCB. Sua atuação centrada entre os trabalhadores rurais acentuou essa violência. "Soldado do partido" (Bezerra, 2011: 457), foi eleito deputado federal, atuou na clandestinidade, sofreu perseguições, resistiu às tentativas de golpe e assassinato, foi preso e torturado diversas vezes.

Sua dedicada atuação política compõe a posição sinalizada por Florestan Fernandes de Gregório como um revolucionário ideal, um representante do povo. $\mathrm{O}$ sucesso de seu livro de memórias - publicado em 1979 - parece fortalecer essa posição.

Deste modo, o objetivo deste artigo é debater as razões simbólicas da posição ocupada por Gregório, partindo das experiências em torno da noção de trabalho. Em

\footnotetext{
${ }^{1}$ Universidade Federal do Rio de Janeiro, Brasil.

2 Fragmento do texto publicado na reedição de suas Memórias, em 2011 (Bezerra, 2011: 624) Originalmente publicado em 27 de outubro de 1983, na página 3 do jornal Folha de São Paulo, integra também o livro Que tipo de República é essa? (2. Ed., São Paulo, Globo, 2007, p. 269-273)
} 
outras palavras, procuramos analisar como Gregório articula a narrativa de sua história de vida - e as experiências em torno do trabalho - como fator legitimador dessa identidade popular e também como motor das lutas protagonizadas por ele.

Em seu livro de memórias Gregório descreve o período entre 1900, ano de seu nascimento, e 1969, quando foi para Moscou, exilado, após ser trocado - junto com outros 14 presos políticos - pelo embaixador norte-americano Charles Burke Elbrick ${ }^{3}$. Em suas $591^{4}$ páginas, Gregório descreve sua infância como trabalhador rural no interior de Pernambuco, o período de escravidão imposto por uma família de latifundiários de Recife, os trabalhos como ajudante de frete, pedreiro, vendedor de jornal, o período no Exército brasileiro, seu ingresso no Partido Comunista Brasileiro (PCB) e toda sua vida partidária.

O primeiro volume das Memórias ${ }^{5}$ de Gregório Bezerra foi lançado em 1979 pela Editora Civilização Brasileira. Foi um ano movimentado na vida política do Brasil, governado por João Baptista de Oliveira Figueiredo. Um ano antes, em 1978, era revogado o $\mathrm{AI}-5^{6}$, dando início ao longo e tardio processo de transição rumo à democracia. O ano de 1979 foi marcado pelo estabelecimento do pluripartidarismo e pela Lei da Anistia $^{7}$, que permitiu o retorno de alguns presos políticos exilados, entre eles o próprio Gregório Bezerra. É nesse contexto de importantes mudanças que suas memórias são publicadas, passando a ter enorme relevância ${ }^{8}$. Gregório foi um dos

\footnotetext{
${ }^{3}$ Charles Burke Elbrick era embaixador dos Estados Unidos no Brasil no ano de 1969. Foi sequestrado pela ação do grupo Dissidência da Guanabara - que na ocasião utilizou o nome MR-8 (Movimento Revolucionário 8 de outubro), em homenagem ao extinto grupo guerrilheiro niteroiense - apoiado pela Ação Libertadora Nacional (ANL), comandada por Marighella. O sequestro tinha como meta inicial tirar da cadeia o líder estudantil Vladimir Palmeira, entre outros presos políticos (Berquó, 1997; Tavares, 1999).

${ }^{4}$ As referências utilizadas nesse artigo se referem à edição lançada em 2011 pela editora Boitempo.

${ }^{5}$ Parte dessas memórias está para ser retomada com a produção do filme Histórias de um valente, de Cláudio Barroso.

${ }^{6} \mathrm{O}$ Ato institucional número 5, ou AI-5, foi o quinto de uma série de decretos emitidos ao longo do período de regime militar no Brasil. Suspendendo várias garantias constitucionais, o AI-5 sobrepunha-se à Constituição de 24 de Janeiro de 1967, bem como às constituições estaduais, concedendo poderes extraordinários ao Presidente da República. O AI-5 marcou um período mais repressor do regime, assumido pela chamada linha dura do Exército.

7 Promulgada em agosto de 1979, a lei da Anistia ( $n^{\circ}$ 6.683) resultou de movimentações políticas da sociedade civil - a chamada Campanha pela Anistia. Seu objetivo era a defesa de uma anistia ampla, geral e irrestrita a todos os brasileiros exilados durante o regime militar. A lei é reconhecida como o primeiro ato marcante do governo do General João Batista Figueiredo pelo processo de abertura política no país.

${ }^{8}$ É interessante observarmos o contexto político do ano do relançamento de suas memórias, em 2011, num período marcado pelos debates em torno da criação da Comissão da Verdade e de retorno à história do período do regime militar no Brasil. O sucesso do relançamento de suas memórias parece demonstrar como elas ainda operam como uma ferramenta política importante, revelando também o apelo que a imagem de Gregório Bezerra ainda possui, mesmo vinte e nove anos após sua morte. A Comissão foi criada pela Lei 12528/2011 e instituída em maio de 2012 e tem por finalidade apurar as graves violações de Direitos Humanos, praticadas por agentes públicos, ocorridas entre 18 de setembro de 1946 e de
} 
principais presos políticos do regime militar (1964-1985). A mando do coronel Darcy Villocq, foi barbaramente torturado e obrigado a andar pelas ruas de Recife, em um dos episódios mais conhecidos desse período em todo país. Sua trajetória estava vinculada àquele período e representava, naquele momento, o rompimento do silêncio imposto até então. Suas memórias têm, portanto, um forte caráter político: pertencem a um homem público, comunista, preso durante 23 anos de sua vida e filiado a um partido de esquerda colocado muitas vezes na ilegalidade.

As páginas publicadas de suas memórias foram escritas durante o exílio em Moscou, período em que continuou atuando politicamente contra o regime militar implantado no Brasil. Suas memórias foram escritas por motivações próprias, num período particularmente frágil, de doença e exílio forçado. Em função da tortura sofrida em 1964 e dos anos de prisão - sem qualquer possibilidade de atendimento médico adequado -, Gregório encontrava-se com a saúde fragilizada, agravada pela idade avançada. Assim, podemos supor a relevância que este contexto de prisão, exílio, saudade, distância das atividades que realizava no Brasil e fragilidade física tivera na construção dessas memórias. O desejo de que o lançamento do livro fosse quase concomitante ao seu retorno no exílio foi possível pelo interesse de Ênio Silveira, membro do PCB e dono da editora da Civilização Brasileira ${ }^{9} \mathrm{Na}$ Europa, tendo acesso às páginas das memórias Ênio Silveira teria se interessado pela publicação do livro.

Todos esses dados são relevantes para formularmos a hipótese de que suas memórias se inserem num forte contexto político de denúncia, de disputas políticas, o que fica mais claro se observarmos a preocupação de Gregório em listar os nomes dos torturados e torturadores em diversos trechos do livro, construindo um verdadeiro arquivo político da tortura no Brasil durante os períodos ditatoriais do século XX. Suas memórias podem ser compreendidas como denúncias também por sua preocupação em narrar algumas situações de violência e exploração sofridas por milhares de camponeses. É digno de nota que sua escrita tenha sido posterior à publicação do livro "Eu, Gregório Bezerra, acuso!" (escrito nos dias passados na prisão); e concomitante à elaboração de um dossiê sobre o regime político vigente no país, como mostra este trecho do epílogo:

Para combater esse Estado clandestino, tratei de recolher amplo material informativo sobre as vítimas de tortura e os torturadores. Possuo atualmente um amplo dossiê, ainda não sei como vou utilizá-lo. No momento em que dou os retoques finais

de Direitos Humanos, praticadas por agentes públicos, ocorridas entre 18 de setembro de 1946 e 5 de outubro de 1988

${ }^{9}$ A editora Civilização Brasileira foi responsável pela publicação de uma vasta literatura comunista, com lançamento de autobiografias de militantes de esquerda - como a de Gregório, Dias Gomes, Gullar, Flávio Tavares e Octávio Brandão. 
nessas minhas Memórias, achamo-nos no segundo semestre de 1978 e a imprensa brasileira já está falando do assunto com crescente desenvoltura: os jornais e as revistas estão lembrando os casos de prisioneiros políticos que foram assassinados ou então "desapareceram" nas mãos de seus verdugos. É imprescindível que todos os democratas mobilizem todas as suas energias para que crimes assim nunca mais voltem a ocorrer (Bezerra, 2011: 589).

Notemos também nessas linhas o reconhecimento de Gregório quanto à importância da publicação de suas memórias, especialmente no mencionado contexto político de 1978/79. Assim, não parece exagero compreender o livro como uma forma de rompimento do silêncio e do exílio imposto a ele, exílio que não se restringiu à vida no exterior, mas também aos anos de prisão, tortura e clandestinidade.

Definir suas Memórias como uma ferramenta política passa pela compreensão da própria memória como um elemento em disputa, como sugere Michael Pollak (1989, 1992). Nos artigos "Memória, Esquecimento e Silêncio" (Pollak, 1989) e "Memória e Identidade social" (Pollak, 1992), o autor centra sua atenção nas zonas de sombra da memória, nos silêncios, refletindo sobre os processos de deslocamento e negociação envolvidos na definição de uma história ou de uma memória oficial. As memórias de Gregório podem ser compreendidas dentro de uma esfera marginal, subterrânea, como um elemento divergente da Memória oficial em determinados contextos; como uma memória que denuncia reiteradamente as histórias representadas como "oficiais". Como uma voz importante, capaz de fazer denúncias, como mais um elemento que entra em disputa na definição das memórias nacionais, capaz de sugerir outras histórias e outros pontos de vista, desestabilizando a história oficial.

Gregório consegue construir em seu livro uma memória subterrânea crítica à própria história do Brasil, pois passa por momentos diferentes dessa história: trabalhou no campo no início do século, num período de pós-abolição da escravidão; participou das organizações proletárias em 1917 (sendo preso pela primeira vez); integrou o movimento antifascista da década de 1930; acompanhou todo o período político governado por Getúlio Vargas; foi um articulador importante em diferentes momentos da organização dos trabalhadores no campo (especialmente no início da década de 1950) e, por fim, atuou diretamente contra o regime militar iniciado em 1964.

Compreender a relevância e legitimidade de suas memórias nos leva à questão colocada no início deste artigo, a saber, a compreensão da posição ocupada por Gregório como um "revolucionário ideal". O trabalho de enquadrar uma memória e transformá-la em um objeto político de denúncias parte de uma exigência de credibilidade e legitimidade, que - como alerta Pollak - depende da coerência dos discursos. Se para Gregório era fundamental apresentar suas próprias versões dos fatos, tornando suas memórias um símbolo de luta, era preciso legitimidade para fazer com que suas memórias tivessem escutas e ressonância. É nesse sentido que podemos 
compreender a importância de suas memórias, pois as experiências vividas - e narradas por Gregório, parecem ter um peso para compreendermos a construção e a legitimidade de sua imagem; uma vez que sua história de vida é frequentemente associada ao seu caráter de revolucionário exemplar.

Ao longo da pesquisa desenvolvida no último ano, exploramos um vasto material sobre Gregório Bezerra - como entrevistas, panfletos, reportagens, livros, cartas pessoais - bem como entrevistamos pessoas ligadas a ele durante sua vida. Analisando este material, foi possível perceber como certas representações são recorrentes quando se remete à sua figura. Sua solidariedade, humanidade, disciplina, força, capacidade de trabalho, coragem, doçura, humildade, são frequentemente citados para descrevê-lo. Estas qualidades aludem a outro aspecto crucial: Gregório é lembrado como um dos membros do partido mais próximos ao povo, e que melhor conseguia se comunicar, falar ao povo. Tais características remetem à ideia de que Gregório seria um verdadeiro revolucionário ou uma espécie de revolucionário legítimo, popular.

Como um membro exemplar do PCB, é o próprio Gregório quem responde, num primeiro momento, o que significa ser um revolucionário: é estar organizado no partido vanguarda da classe trabalhadora; se dedicar à causa de transformar radicalmente a sociedade, colocando-se a serviço da classe trabalhadora. Daí o ingresso no partido ser um elemento central. Por outro lado, através das leituras de suas memórias, percebemos como Gregório reconhece certos atos não revolucionários de alguns membros do partido. Numa análise mais atenta, podemos questionar até que ponto o ingresso no partido garante o caráter de revolucionário exemplar - ou, pelo menos, do revolucionário como Gregório é representado. Dito de outra forma, nem todo membro do PCB no século XX é defendido como um revolucionário, ou um comunista exemplar, tal como Gregório. Podemos então seguir algumas pistas que nos permite compreender este seu caráter excepcional.

A partir desse ponto, podemos elaborar algumas questões que guiarão este artigo: como se construiu essa imagem? Porque essas características são tão destacadas quando se fala de sua figura? O que significa ser um revolucionário exemplar? Quais são as diferenças entre Gregório e outros militantes do PCB? Quais são as experiências que identificam Gregório ao povo? E, mais especificamente, como as memórias e narrativas em torno do trabalho parecem relevantes para compreendermos essas questões? Partimos da hipótese de que a resposta dessas perguntas recai sobre uma representação de sua trajetória, especialmente do período da infância e juventude.

$\mathrm{O}$ estabelecimento da identidade entre Gregório e o povo parte de uma série de representações acerca desse povo, ou, mais especificamente, desse camponês. Ao definilo como um "representante popular" se está lançando mão de uma série de pressupostos, 
de um conjunto de qualidades inerentes a esse "povo" - como se sua trajetória fosse capaz de, por ela mesma, identificar e legitimar determinadas qualidades em Gregório.

Quando definimos que Gregório é a legítima expressão do povo - que tem uma identidade popular e que, por isso mesmo, pode falar ao povo com legitimidade estamos chamando atenção para determinados símbolos, valores, hábitos, relacionados ao que compreendemos como povo ou popular. Representações presentes em sua memória e nas falas a respeito de sua importância política.

Nesse sentido, podemos analisar as formas pelas quais Gregório conjuga algumas imagens e valores associados ao universo popular com sua trajetória e sua atuação política. Ao valorizar em suas memórias as experiências de fome, seca, trabalho e exploração, Gregório não está se remetendo a uma experiência distante ou fortuita.

Mas, ao contrário, está falando de uma experiência específica, através da qual se compartilha uma identidade, uma comunhão com o "povo explorado e oprimido". Mais do que isso, está identificando algumas experiências e valores típicos do povo e construindo uma imagem do que seria esse povo. Assim, quando Gregório destaca que viveu determinadas experiências e foi educado em certa formação moral, ele está defendendo também uma identidade com esse povo.

Esta relação de "herança" - base de sua identidade popular - é descrita em diferentes formas ao longo do livro de memórias. Três aspectos demonstram de forma mais clara essa posição: a narrativa que indiquem ao compartilhamento de experiências comuns com o "povo explorado e oprimido" - como já apontado no último parágrafo -, a defesa da posição de solidariedade camponesa e, por fim, a relação entre a sociabilidade camponesa e a ética do trabalho. Neste artigo, buscaremos nos focar na terceira esfera, apontando a relevância de categorias como força, trabalho e honra.

Nesse sentido, um dos principais aspectos dessa trajetória foi a luta pela sobrevivência, arte ensinada a Gregório desde muito cedo. Na barriga da mãe, só podia nutrir-se com suas "entranhas enfraquecidas": Gregório nasceu faminto, e faminto permaneceu durante toda sua infância e juventude. Trabalhou desde muito cedo - e nunca parou de trabalhar, especialmente com o ingresso no partido. $\mathrm{O}$ trabalho precoce não ressentiu Gregório, nem o deixou rancoroso com sua mãe; mas, ao contrário, o trabalho na roça com sua família é motivo de orgulho e de honra. Quando afirma que sua escola foi a "preparação do roçado" e completa "foi uma excelente escola", parece demonstrar que algum ganho foi adquirido nesse trabalho. As lições que aprendera parecem se relacionar intimamente com sua concepção de ética, dignidade, respeito e 
capacidade de luta. Dimensão da vida em família que recai sobre a ética do trabalho camponesa, fortemente baseada na "pedagogia do sofrimento" (Comerford, 2003), segundo a qual, o aprendizado da honestidade, da dignidade e da respeitabilidade só são obtidos com muito trabalho. Através do sofrimento e do trabalho, a criança seria formada, sociabilizada e aprenderia a lidar com as categorias básicas da economia moral da família.

O trabalho é base da fase central da socialização e formação ética da criança; sendo a principal modalidade de imposição da autoridade dos pais e da manutenção das relações familiares. É através do trabalho na família que os filhos aprendem a respeitar e obedecer aos pais e a tê-los como exemplo de capacidade de luta, de dignidade, de honra (Comerford, 2003).

A arte de lutar, a honestidade, o respeito pelas autoridades paternas e por sua avó, a ética do trabalho camponesa, são elementos centrais de suas memórias de infância no interior de Pernambuco. No mesmo sentido, de sua mãe nota que "era forte, apesar de tudo" (Bezerra, 2011: 35). De modo semelhante descreve a força de todos seus vizinhos e da "grande massa camponesa". Com a morte de sua mãe, a avó passou a ocupar um lugar central na educação de Gregório, sendo um exemplo para sua formação. A aptidão para o trabalho, a força de vontade, a disciplina e honestidade de sua avó são também destacadas por Gregório, revelando os exemplos que aprendeu com ela:

\begin{abstract}
Minha avó atravessou estoicamente todos os flagelos das secas, desde o período de 1832 até 1918 , quando faleceu. Era dotada de uma força de vontade férrea e de ânimo muito forte; irredutível em suas opiniões, mãe excelente, boa sogra, ótima avó. Amiga leal de todos que a conheciam. Honesta acima de tudo, terrivelmente intransigente naquilo que não estava coerente com sua formação. Católica até a medula, embora não frequentasse a igreja. Trabalhadora e asseada. (...) Ela, minha avó, fizera mais de trezentos partos. Nunca cobrou um tostão em pagamento. Mesmo quando a fome era a mais negra em sua casa. O seu argumento era: 'O sabê da pessoa é dado por Deus, não lhe pertence, e sim ao senhor Deus, para servi aos necessitados, e não pra vendê ele aos qui precisam'. (ibidem: 74)
\end{abstract}

Através da prática do trabalho, dos constrangimentos, das lições e exemplos de sua avó, de sua mãe, de seus tios e vizinhos, Gregório demonstra a capacidade adquirida de lidar com as categorias da economia moral da família camponesa. Com o exemplo do "povo, profundamente sofrido, porém jamais vencido" 10 (ibidem: 73), Gregório aprendeu a capacidade de viver no limite, de lutar, de trabalhar e, principalmente, de

\footnotetext{
${ }^{10}$ Para este aspecto, vale destacar o relato de Elio Gaspari sobre Gregório: “A ANL fizera um aceno de cortesia ao Partidão, incluindo no resgate de Elbrick o nome mais famoso e sofrido dos seus presos políticos [Gregório Bezerra]" (Gaspari, 2002: 145)
} 
honrar o fruto de seu trabalho. Mesmo com sua saída no campo, Gregório aplicou os preceitos da "pedagogia do sofrimento" da socialização camponesa nos trabalhos realizados nas ruas de Recife, no Exército e no partido.

Nesse sentido, o trabalho - e sua honra pela capacidade de trabalhar - é sempre realçado em suas narrativas. Há uma preocupação em se mostrar bom de trabalho (expressão minha); um esforço para demonstrar que é um trabalhador e que sempre foi o que lhe confere também uma legitimidade. Acompanhando suas memórias, percebemos como Gregório chama atenção para esta capacidade desde muito cedo, quando valoriza os elogios que recebia por sua boa aptidão para o trabalho. Ao comentar sobre o trabalho na roça, destaca o comentário de seus tios: "O Grilo é um menino esperto, ele nunca teve priguiça pra nada. Tudo qui si manda fazê ele fai." (ibidem: 96). Como gazeteiro, obtinha sucesso e era um dos que mais vendia jornais, conseguindo uma boa freguesia. Quando trabalhou como meia-colher na construção civil, se esforçou para aprender rapidamente as técnicas empregadas, conseguindo logo um aumento pelo bom trabalho prestado: "O meu salário de 1.500 réis subiu para 1.800 réis depois de duas semanas, devido à quantidade e à qualidade de massa que fazia" (ibidem: 160). No Exército vangloriava-se por "alguns elogios pelos bons serviços prestados à pátria" (ibidem: 190): "eu trabalhava muito e me impus pelo trabalho" (ibidem: 175). E completa com um elogio que recebera de um coronel: "foi o mais disciplinado e trabalhador que já passou pelo batalhão" (ibidem: 211). Ao justificar o sucesso inicial de sua militância no setor militar, declara que não provocava desconfianças, pois "desfrutava de certo prestígio aos olhos da oficialidade devido à minha capacidade de trabalho como instrutor" (ibidem: 233). No partido, Gregório orgulhava-se por sua capacidade de realizar tarefas partidárias e criticava os militantes que não se propunham a realizar o mesmo esforço.

Em outros trechos de sua narrativa, Gregório destaca a centralidade de categorias como trabalho, dignidade, honra e orgulho em sua trajetória. Por exemplo, quando afirma que não pediria esmolas "não só porque tinha vergonha como porque me sentia capaz para qualquer trabalho dentro dos limites de minhas forças.” (ibidem: 120), Gregório está valorizando sua capacidade de luta, de esforço através do qual poderia ganhar seu sustento. Em outra ocasião, ao comentar sobre seu breve envolvimento com jogos de azar, apresenta sua surpresa com a forma fácil com que ganhou dinheiro, revelando os constrangimentos pela ausência de qualquer esforço e trabalho: "Fiquei 
horrorizado por ter ganho vinte mil-réis sem me custar uma gota de suor. Para ser franco, fiquei com um remorso dos diabos" (ibidem: 142).

Vale a pena nos retermos na análise das categorias orgulho, dignidade, honra ${ }^{11} \mathrm{e}$ vergonha, recorrentes nas memórias. Partindo da análise das próprias concepções elaboradas por Gregório de termos como honra, honestidade e orgulho, podemos sublinhar a valorização de um "sentimento de dignidade" (Teixeira, 1998): noções que indiquem uma disciplina, e apontem para certas formas de conduta são relevantes para compreendermos estes aspectos de suas memórias. Na visão de Gregório, trabalho aparece como dignificação, como orgulho pela capacidade de criar, de produzir; e é pelo trabalho que Gregório pautou sua formação ética, sua dignidade. O dinheiro de um trabalho desonesto, ou de um trabalho fácil, não teria valor, pois não teria honra; em outras palavras, há uma valorização, uma positividade nessa produção e nesse trabalho. Nesse sentido, não é aleatório que Gregório chame atenção para sua capacidade física de resistência, valorizando seu corpo forte, apto para qualquer atividade.

Indo um pouco além, as lições tiradas no trabalho parecem vinculadas à própria concepção de revolucionário que ele defende: trabalho, disciplina, sacrifício também se inserem na economia moral do partido, ainda que adotem significados e sentidos específicos. E esse é um ponto interessante, pois Gregório se destacava no partido justamente por sua capacidade de trabalho, sendo frequentemente descrito como "um homem de ação" dentro do partido, com mais aptidão e vontade para o trabalho direto com as massas. Ao percorrer suas memórias e acompanhar a descrição das diferentes atividades empreendidas ao longo de sua vida partidária, podemos perceber a valorização dessa característica. Essa capacidade de ação e de trabalho, por sua vez, parece destaca-lo de outros membros do partido, principalmente dos dirigentes: suas atividades não parecem ser as mesmas daqueles que ocupavam os cargos máximos, comumente associados às ocupações mais intelectualizadas, burocráticas ou mais urbanas.

Até agora, destacamos como Gregório buscava manter uma identidade com seu universo de origem camponesa, observando como construía essa fidelidade a partir de suas memórias. Desse modo, apontamos como as lições que tivera no trabalho familiar,

\footnotetext{
${ }^{11}$ Esta discussão remete à definição de honra, elaborada por Pitt-Rivers: "L'honneur est la valeur qu'une personne possède à sés propes yeux mais c'est aussi ce qu'elle vaut au regard de ceux qui constituent as société. C'est Le prix auquel elle s'estime, l'orgueil auquel esse prétend, em même temps que la confirmation de cette revendication par La reconnaissance sociale de son excellence et de son droit à lá fierté." (Pitt-Rivers,1983: 18)
} 
na economia moral da família camponesa - iniciado com o ganho da enxadinha, ainda com quatro anos - se relacionavam à sua concepção de capacidade de luta, honra, respeito e dignidade. Essas lições, por sua vez, são mantidas com o ingresso no partido: sua capacidade de lutar, trabalhar e honrar o fruto deste trabalho é resignificada na esfera da militância. Não por acaso, Gregório se define como um funcionário do PCB, motivando toda lógica de deveres, honras e obrigações envolvidos nessa relação.

Sua capacidade de se mostrar um trabalhador - bom de trabalho - parece lhe conferir também uma legitimidade como um representante popular. Ser realmente um trabalhador, ter um gosto pelas atividades mais práticas dentro do partido, parecem indicar uma identidade com aqueles que iam ouvir seus comícios e reuniões. Aníbal Mendonça e Roberto Arraes ${ }^{12}$ relembram a facilidade com que Gregório falava aos camponeses, justamente por conhecer as técnicas de trabalho presentes naquele universo. Em entrevista concedida durante o trabalho de campo desta pesquisa, Aníbal comenta:

\begin{abstract}
Todos os camponeses com quem ele lidou, tinha ele como lenda porque sabiam disso [do fato dele ter uma origem camponesa]. E outra coisa: As coisas que acontecem no campo, no corte da cana, ele sabia de tudo. Porque tinha que fazer aquilo, como tinha que aproveitar isso... [Como] criar uma galinha, ou criar um bode e engordar o porco... Um bocado de coisas. [Como] Tinha que zelar pela água, pra não pegar doenças, tudo isso ele sabia. E ao mesmo tempo era um misto de conselheiro,de amigo, de pessoas que querem o bem de todos... E outra coisa: ele também não se fazia de rogado, de ir junto com eles, de cortar cana. ${ }^{13}$
\end{abstract}

Nesse sentido, podemos compreender como a afirmação deste gosto pelo trabalho próximo do povo, a preocupação em mostrar-se um bom trabalhador e, em demonstrar a força física para as atividades partidárias, contribui para a posição excepcional ocupada por Gregório dentro do partido. As razões dessa identidade, mais uma vez, parecem explicadas pela trajetória comum: Gregório teria um gosto pelas atividades mais práticas porque se identificaria com ela, uma vez que compartilharia dos mesmos valores e experiências - é nesse sentido que podemos compreender sua facilidade em se aproximar dos camponeses pelos conhecimentos e domínios das técnicas de trabalho, como, por exemplo, no manuseio do corte da cana.

Ao distanciar-se do trabalho comum aos dirigentes do partido, Gregório parece reafirmar seu vínculo com as massas, sublinhando sua identidade popular e camponesa.

\footnotetext{
${ }^{12}$ Aníbal Mendonça, membro do PCB, que conviveu com Gregório nos anos de exílio em Moscou, e Roberto Arrais, político, membro do PCB, que o acompanhou no período posterior ao exílio, já no Brasil.

${ }^{13}$ Trecho da entrevista concedida por Aníbal Mendonça durante o trabalho de campo. Realizada na cidade de Recife, no escritório do entrevistado, no dia 26 de agosto de 2012.
} 
Ao longo de suas memórias, narra alguns conflitos que tivera com membros do partido, demonstram como trabalho, coragem, audácia, proximidade com o povo e simplicidade parecem ser - do ponto de vista de Gregório -, categorias centrais de um comunista. A estes elementos, por sua vez, Gregório opõe a falta de ação, de audácia, a arrogância e o gosto pela ilegalidade de alguns membros (Rodrigues, 2007; Vinhas, 1982). Assim, por exemplo, durante uma briga com Vilar ${ }^{14}$, Gregório comenta: "a estima que eu merecia do partido não tinha sido conquistada por carreirismo nem por bajulações. Tinha sido conquistada no trabalho com as massas". (Bezerra, 2011: 455). Ao narrar este episódio, Gregório mais uma vez valoriza o trabalho empregado nas atividades partidárias, e o prestígio com as camadas populares, buscando legitimar-se a partir destes elementos.

Concluindo, ao defender essa identidade popular a partir de um trabalho mais prático, simples, de grande coragem e audácia - distante das atividades mais intelectualizadas -, Gregório passa a ocupar uma posição mais visível, de maior destaque e prestígio com a massa. Destacando sua capacidade de trabalho e simplicidade no relacionamento com o povo - e criticando os membros do partido que não contavam com a mesma disposição -, Gregório consegue honrar seu trabalho como funcionário do partido. Essa satisfação, por sua vez, se relaciona à constante preocupação em demonstrar-se bom de trabalho. Ser capaz de ir até o campo, se "sujar nos lamaçais", mexer com o corte da cana, e, principalmente, se identificar com estas práticas e valores, parece colaborar para o prestígio e reconhecimento de Gregório entre os trabalhadores. E Gregório se orgulha dessa característica, vinculando este trabalho à sua trajetória, como fica expresso nesse trecho: "O partido tinha me designado para trabalhar no campo. Foi uma tarefa que aceitei de mão beijada, porque eu também sou de origem camponesa e fui assalariado agrícola desde os sete anos de idade".

\section{Referências}

BERQUÓ, Alberto. O sequestro dia a dia. Rio de Janeiro: Editora Nova Fronteira, 1997

BEZERRA, Gregório . Eu, Gregório Bezerra, acuso! (Editora própria do PCB), 1967.

. Memórias, 1900-1983. São Paulo: Boitempo, 2011.

\footnotetext{
${ }^{14} \mathrm{O}$ "camarada de nome Villar", foi professor de Gregório no curso Stálin, oferecido pelo partido para a qualificação dos membros da direção central e das direções estaduais do partido.
} 
COMERFORD, John Cunha. Fazendo a luta. Sociabilidades, falas e rituais na construção de organizações camponesas. Rio de Janeiro, Editora Relume Dumará, 1999.

Como uma família. Sociabilidade, territórios de parentesco e sindicalismo rural. Rio de Janeiro, Editora Relume Dumará, 2003.

FERNANDES, Florestan. "Integridade e Grandeza”. In: Bezerra, Gregório. Memórias, 19001983,. São Paulo: Boitempo, 2011.

RODRIGUES, Leôncio Martins. "O PCB: os dirigentes e a organização". In História Geral da Civilização Brasileira - Sociedade e política (1930-1964). Rio de Janeiro, Editora Bertrand, 2007.

PITT-RIVERS, Julian. Anthropologie de l'honneur: La mésaventure de Sichem. Paris: Le Sycomore, 1983.

POLLAK, Michel. Memória, esquecimento e silêncio. Estudos Históricos. Rio de Janeiro, v. 2, n. 3, CPDOC, 1989, pp. 3-15.

Memória e identidade social. Estudos históricos. Rio de Janeiro, v. 5, n. 10, CPDOC, 1992, pp. 200-212.

TAVARES, Flávio. Memórias do esquecimento. São Paulo: Editora Globo, 1999.

TEIXEIRA, Carla Costa. A honra da política: decoro parlamentar e cassação de mandato no Congresso Nacional (1949- 1994), Rio de Janeiro, Editora Dumará, 1998

VINHAS, Moisés. O Partidão: a luta por um partido de massas 1922- 1974. São Paulo, Editora Hucitec, 1982.

Recebido em: 08/08/2013

Aprovado em: 12/08/2013 